\title{
Wide Variability in Prethrombectomy Workflow Practices in the United States: A Multicenter Survey
}

\author{
(D) A.P. Kansagra, DG.C. Meyers, DM.S. Kruzich, DD.T. Cross III, and (D)C.J. Moran
}

\begin{abstract}
BACKGROUND AND PURPOSE: Clinical outcomes in patients with acute ischemic stroke caused by large vessel occlusion depend on the speed and quality of workflows leading to mechanical thrombectomy. In the absence of universally accepted best practices for workflow, developing stroke hospitals can benefit from improved awareness of real-world workflows in effect at experienced centers. To this end, we surveyed prethrombectomy workflow practices at stroke centers throughout the United States.
\end{abstract}

MATERIALS AND METHODS: E-mail and phone interviews were conducted with neurointerventional team members at 30 experienced, endovascular-capable stroke centers. Questions were chosen to reflect workflow components of triage, team activation, transport, case setup, and anesthesia.

RESULTS: There is wide variation in prethrombectomy workflows. At $53 \%$ of institutions, nonphysician staff respond to stroke alerts alongside physicians. Imaging triage involves noninvasive angiography or perfusion imaging at $97 \%$ and $63 \%$ of institutions, respectively. Neurointerventional consultation is initiated before the completion of neuroimaging at $86 \%$ of institutions, and the team is activated before a final treatment decision at $59 \%$. The neurointerventional team most commonly arrives within 30 minutes. Patients may be transported to the neuroangiography suite before team arrival at $43 \%$ of institutions. Procedural trays are set up in advance of team arrival at $13 \%$ of centers; additional thrombectomy devices are centrally stored at $54 \%$. A power injector for angiographic runs is consistently used at $43 \%$ of institutions. Anesthesiology routinely supports thrombectomies at $67 \%$ of institutions.

CONCLUSIONS: Prethrombectomy workflows vary widely between experienced centers. Improved awareness of real-world workflows and their variations may help to guide institutions in designing their own protocols of care.

ABBREVIATIONS: LVO = large vessel occlusion; $\mathrm{NI}=$ neurointerventional

$\mathbf{R}$ ecent clinical trials have conclusively demonstrated the outcome benefit of mechanical thrombectomy in selected patients with acute ischemic stroke caused by large vessel occlusion (LVO). ${ }^{1-5}$ For these patients, the likelihood of a good neurologic outcome depends on the time elapsed between symptom onset and revascular-

Received June 13, 2017; accepted after revision July 13.

From the Mallinckrodt Institute of Radiology (A.P.K., D.T.C., C.J.M.) and Departments of Neurosurgery (A.P.K., D.T.C., C.J.M.) and Neurology (A.P.K.), Washington University School of Medicine, St. Louis, Missouri; and Barnes-Jewish Hospital (G.C.M., M.S.K.), St. Louis, Missouri

Paper previously presented at: Annual Meeting of the Society of Neurolnterventional Surgeons, July 25-29, 2016; Boston, Massachusetts, and Annual Meeting of the Society of Vascular and Interventional Neurology, November 16-29, 2016;

Brooklyn, New York.

Please address correspondence to Akash P. Kansagra, MD, MS, Mallinckrodt Institute of Radiology, 510 South Kingshighway Blvd, Campus Box 8131, Saint Louis, MO 63110; e-mail: apkansagra@gmail.com; @AkashKansagra

三 Indicates article with supplemental on-line table.

http://dx.doi.org/10.3174/ajnr.A5384 ization. $^{6-11}$ Indeed, the negative results of 3 earlier clinical trials ${ }^{12-14}$ may be attributed in part to prolonged treatment delays. ${ }^{8,15-17}$

These developments have sparked considerable interest in designing efficient workflows for diagnosis and treatment that can reduce the time between patient presentation and thrombectomy. ${ }^{7,18-20}$ Although many of these efforts have been successful, there is currently no broadly accepted consensus for optimal prethrombectomy workflow. In the absence of such consensus, individual centers have implemented a heterogeneous assortment of workflows that may be influenced by individual physician preference, institution-specific factors, or incomplete awareness of effective solutions at competing institutions.

Given the overall importance of prethrombectomy workflow on time to treatment, improved guidance is needed for hospitals looking to redesign their own systems to care for patients with LVO. Understanding the range of current practice patterns is an important first step toward that goal. In this work, we aimed to attain a broader perspective on prethrombectomy workflow prac- 


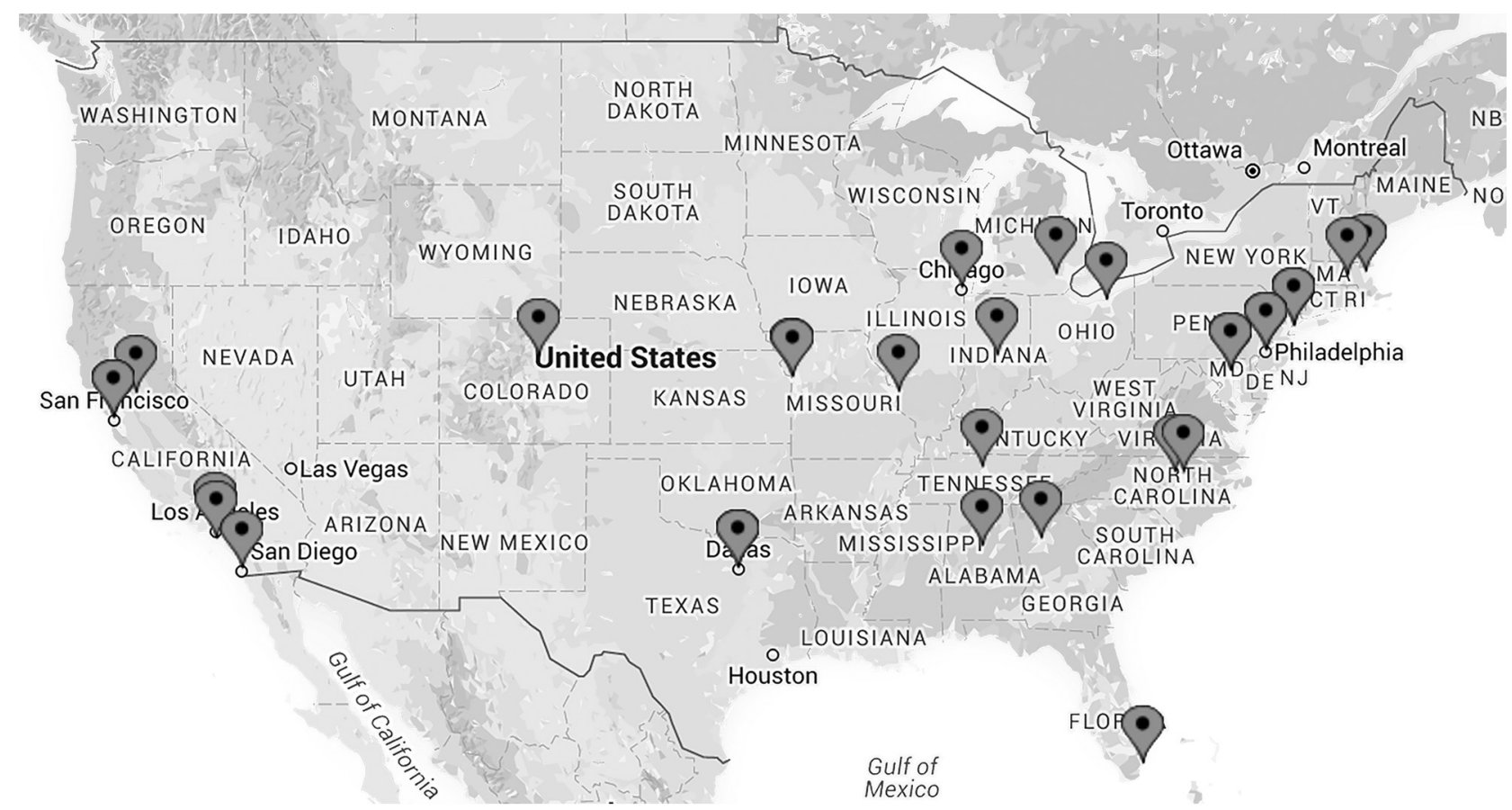

FIGURE. Locations of stroke centers responding to the survey.

tices by conducting a nationwide survey of practices in effect at experienced stroke centers, identify highly consistent workflow steps that may indicate general agreement on best practices in real-world conditions, and recognize areas of greater workflow variability that may suggest that such a consensus has yet to emerge.

\section{MATERIALS AND METHODS}

Institutional review board approval was obtained for this survey. Target institutions were identified based on American Heart Association certification as an Advanced Comprehensive Stroke Center or endovascular-capable Advanced Primary Stroke Center, or the presence of a fellowship-level neurointerventional (NI) training program. Contact information was obtained from institutional Web sites and/or hospital operators at each of these centers, and an attempt was made to contact NI team members (physicians, technologists, and nurses who are directly involved in thrombectomy procedures) via telephone during normal business hours between August 2015 and November 2015. If this initial attempt was unsuccessful, a second attempt was made between 1 and 3 weeks later.

At centers where contact was successfully established, interviews were conducted by experienced NI technologists with NI team members via telephone or e-mail, depending on the preference of the person being surveyed. Each of these centers reported performing at least 50 thrombectomy cases in the previous 12 months. Survey questions were chosen based on perceived areas of opportunity to reduce time to treatment or workflow complexity at our institution, as suggested by a multidisciplinary group of physicians, technologists, and nurses while streamlining our own protocol for the management of patients with LVO. Questions were categorized into primary workflow components of triage, team activation, transport, case setup, and anesthesia. Respon- dents were asked to consider a typical patient when providing answers. Responses were stored in an electronic data base. No compensation was offered to study participants. Data are reported as simple proportions.

\section{RESULTS \\ Responses}

The complete list of questions and answers is reported in the Online Table. An attempt was made to contact NI team members at 50 different institutions. Of these, 60\% (30/50) responded in whole or in part to the survey (Figure). These institutions included 22 Advanced Comprehensive Stroke Centers, 6 Advanced Primary Stroke Centers, and 2 Massachusetts Designated Primary Stroke Services Hospitals. Of these 30 institutions, 60\% (18/30) included a postresidency NI fellowship training program.

\section{Triage}

Fifty-three percent (16/30) of institutions reported creating an acute response team of nonphysicians to facilitate triage in the emergency department. CT was the preferred imaging technique and was used as the sole modality at 90\% (27/30) of institutions. Noninvasive angiographic imaging was incorporated into routine patient selection at 97\% (29/30) of centers, whereas noninvasive perfusion imaging was routinely used at $63 \%(19 / 30)$ of facilities.

\section{Team Activation}

At 93\% (28/30) of institutions, initial contact with the NI service was directed only to an NI physician-typically the NI fellow at centers with fellowship training programs-rather than the full NI team. Initial contact was made before image acquisition at $86 \%$ $(25 / 29)$ of centers, but activation of the full NI team before reach- 
ing a final decision to treat occurred at only 59\% (17/29) of institutions.

Activation of the full NI team occurred by direct contact from the NI physician at $63 \%$ of institutions (19/30) and through a hospital operator at 23\% (7/30). In total, 97\% (29/30) of institutions had a defined response time requirement for the NI nurses and technologists, most commonly 30 minutes.

\section{Transport}

The emergency department team (including any responding neurologists in the emergency department) took part in transport of the patient to the neuroangiography suite at $87 \%(26 / 30)$ of centers, whereas the NI team was routinely involved in transport at $20 \%(6 / 30)$ of institutions. Patients were permitted to be transported to the neuroangiography suite before NI team arrival at $43 \%(12 / 28)$ of centers.

\section{Case Setup}

The procedural tray was opened by the NI team upon arrival at $90 \%$ (27/30) of institutions. The procedural tray comprised a basic diagnostic angiography tray at $90 \%$ (27/30) of centers, with additional supplies needed for mechanical thrombectomy added as necessary. Additional thrombectomy supplies were stored in a centralized location in the neuroangiography suite at 54\% (15/28) of institutions. A power injector was routinely or variably used at $47 \%$ (14/30) of centers, but was not kept preloaded with contrast at any institution $(0 / 30)$.

\section{Anesthesia}

Members of the anesthesiology service routinely assisted mechanical thrombectomy at 67\% (20/30) of institutions and variably at $7 \%$ (2/30). Regardless of anesthesiology service involvement, the preferred type of anesthesia was conscious sedation at $43 \%$ (12/ $28)$ of centers and general anesthesia at $21 \%(6 / 28)$.

\section{DISCUSSION}

With the goal of maximizing the clinical outcome benefit of mechanical thrombectomy, several groups have described efficient workflows or suggested improvements to facilitate timely thrombectomy in patients with LVO. ${ }^{7,16,18-24}$ These case studies can serve as important prototypes for other hospitals attempting to redesign their own prethrombectomy workflows. However, these prototypes are likely to be heavily influenced by institution-specific factors. As such, hospitals looking to these examples for guidance may not become aware of workflow variations in effect at other experienced centers. By reviewing in aggregate the workflows at many centers rather than just a single facility, our findings offer a more institution-agnostic view of real-world prethrombectomy workflows. Moreover, the considerable heterogeneity we identified in these workflows suggest areas where consensus on universal best practices is not established or does not exist, while also suggesting opportunities for workflow customization tailored to conditions at individual hospitals.

Mirroring the practices in recent positive thrombectomy trials, ${ }^{1-5}$ we found nearly universal use of noninvasive angiography to identify LVO before attempted thrombectomy. However, we also found that nearly two-thirds of institutions rou- tinely used perfusion imaging for patient selection despite the fact that perfusion imaging was not consistently used in the initial trials demonstrating the effectiveness of thrombectomy. ${ }^{2-5}$ Overall, only a small minority of institutions made routine use of MR imaging for patient selection, presumably reflecting resource constraints and the greater time typically required for MR imaging.

One common workflow solution was to have an acute response team of nonphysicians able to respond immediately to cases of suspected LVO alongside neurology and emergency department physicians. These teams are fluent in prethrombectomy workflows and can facilitate timely management in the acute care setting. Several respondents expressed frustration at a perceived lack of awareness among nonspecialists of the need for rapid evaluation in patients with LVO and noted that acute response teams can bridge this awareness gap until emergency department teams gain familiarity with modern reperfusion strategies in LVO.

At most institutions, initial contact occurs with a single NI physician who is responsible in turn for notifying the remainder of the NI team. Some hospitals facilitate this notification process by designating specific personnel to identify and contact the full NI team, freeing the physician to focus on medical decision-making. A large majority of facilities initiate NI consultation on clinical grounds even before the acquisition of neuroimaging necessary for patient selection. This approach ${ }^{25}$ may confer some time benefit, but comes at the cost of more frequent consultation for patients who later prove to have imaging contraindications to thrombectomy (eg, intracranial hemorrhage, absence of LVO, or a large burden of completed infarction). However, we note that though initial NI consultation precedes neuroimaging at most institutions, it is far less common to activate the full NI team before completing the clinical and imaging evaluation necessary to fully assess the appropriateness of thrombectomy. Once the NI team is activated, most hospitals set a mandatory response time for NI team members.

Transport of patients to the neuroangiography suite is most commonly handled by members of the emergency department team. Furthermore, at many facilities, patients can be transported to the neuroangiography suite by the emergency department team before the arrival of the NI team. Even if the NI team is in house, active ownership of the patient transport process by the emergency department team may allow the NI team to work in parallel to set up the neuroangiography suite. Thus, regardless of NI team location, an emergency department-led transport process may help to minimize the actual time penalty associated with team travel and room setup.

Most commonly, a procedural tray is set up by the NI team upon arrival, as opposed to a "dry tray" set up in advance by the NI team or a conventional tray set up by an in-house designee while the NI team travels to the hospital. Each of these approaches has its virtues; setting up the tray in advance of team arrival likely confers a small time benefit, but sacrifices a clear chain of custody for sterile supplies. Regardless of the approach, most NI teams save time by initially opening a basic diagnostic angiography tray, thereby allowing the NI physician to establish arterial access and perform initial angiographic runs while other NI team members 
work in parallel to retrieve additional thrombectomy supplies. Curiously, many centers have not centralized the location of these supplies within the neuroangiography suite-for example, on a supply cart or cabinet dedicated to stroke interventions - which is a simple and straightforward means to facilitate the retrieval of thrombectomy devices and reduce the cognitive burden on NI team members.

The preferred type of anesthesia during thrombectomy procedures is most commonly conscious sedation, possibly reflecting a desire to avoid the time delay of intubation or concern about early data suggesting worsened postthrombectomy outcomes with general anesthesia. ${ }^{26-28}$ Regardless of the type of anesthesia used, members of the anesthesiology service routinely assist thrombectomy at two-thirds of the surveyed institutions. Although our and other investigators' experience is that door-to-puncture times are shortest when the number of teams engaged in the prethrombectomy workflow is minimized, ${ }^{16,22}$ these data suggest that many NI physicians value having more experienced personnel provide sedation and/or anesthesia, thereby allowing NI physicians to concentrate on the technical aspects of the procedure.

There are 3 principal limitations of this work. First, although we have captured details about the degree of workflow variation between hospitals, we cannot evaluate the validity of these workflow variations without knowledge of door-to-puncture times and clinical outcomes, which many hospitals are unwilling or unable to disclose. Thus, although our data may suggest general agreement on highly consistent workflow steps, we cannot define best practices on the basis of patient impact. Second, although the sample size of 30 institutions is sufficient to extract qualitative insights into practice patterns and the general scale of workflow variation, it is not sufficiently large to permit accurate quantitative assessment. Third, all surveyed institutions are experienced stroke centers, which likely skews demographics toward large, academic institutions that may have different infrastructure and resources than smaller, nonacademic centers.

Our results suggest an opportunity for future work to detail the impact of specific workflow variations on clinical outcomes across multiple institutions. However, it is important to note that not all workflow variations will meaningfully impact time to treatment, though all are likely to impact workflow complexity. The benefits of reduced workflow complexity can be difficult to capture in patient-centered clinical outcome data, but may include increased speed, greater capacity to multitask, fewer errors, and decreased cognitive stress, all of which are likely to be important during critical and time-sensitive procedures.

\section{CONCLUSIONS}

Even at experienced stroke centers, there is considerable heterogeneity in real-world workflow processes leading to mechanical thrombectomy. These differences may reflect institution-specific factors or incomplete awareness of workflow variations in effect at other facilities. Knowledge of the range of prethrombectomy workflows seen in actual clinical practice can guide institutions looking to redesign their own systems of care in a manner best suited to their needs.

\section{ACKNOWLEDGMENTS}

The authors thank Ashley Whitehead, RN, for suggesting the need for a multicenter survey.

Disclosures: Christopher J. Moran-UNRELATED: Consultancy: Medtronic, Microvention, Neurana; Payment for Lectures (Including Service on Speakers Bureaus): Medtronic; Travel/Accommodations/Meeting Expenses Unrelated to Activities Listed: Medtronic, Microvention, Neurana.

\section{REFERENCES}

1. Berkhemer OA, Fransen PS, Beumer D, et al. A randomized trial of intraarterial treatment for acute ischemic stroke. NEnglJMed 2015; 372:11-20 CrossRef Medline

2. Campbell BC, Mitchell PJ, Kleinig TJ, et al. Endovascular therapy for ischemic stroke with perfusion-imaging selection. $N$ Engl J Med 2015;372:1009-18 CrossRef Medline

3. Goyal M, Demchuk AM, Menon BK, et al. Randomized assessment of rapid endovascular treatment of ischemic stroke. $N$ Engl J Med 2015;372:1019-30 CrossRef Medline

4. Jovin TG, Chamorro A, Cobo E, et al. Thrombectomy within 8 hours after symptom onset in ischemic stroke. N Engl J Med 2015;372: 2296-306 CrossRef Medline

5. Saver JL, Goyal M, Bonafe A, et al. Stent-retriever thrombectomy after intravenous t-PA vs. t-PA alone in stroke. $N$ Engl J Med 2015; 372:2285-95 CrossRef Medline

6. Fransen PS, Berkhemer OA, Lingsma HF, et al. Time to reperfusion and treatment effect for acute ischemic stroke: a randomized clinical trial. JAMA Neurol 2016;73:190-96 CrossRef Medline

7. Goyal M, Jadhav AP, Bonafe A, et al. Analysis of workflow and time to treatment and the effects on outcome in endovascular treatment of acute ischemic stroke: results from the SWIFT PRIME randomized controlled trial. Radiology 2016;279:888-97 CrossRef Medline

8. Khatri $\mathrm{P}$, Yeatts SD, Mazighi M, et al. Time to angiographic reperfusion and clinical outcome after acute ischaemic stroke: an analysis of data from the Interventional Management of Stroke (IMS III) phase 3 trial. Lancet Neurol 2014;13:567-74 CrossRef Medline

9. Mazighi M, Chaudhry SA, Ribo M, et al. Impact of onset-to-reperfusion time on stroke mortality: a collaborative pooled analysis. Circulation 2013;127:1980-85 CrossRef Medline

10. Menon BK, Sajobi TT, Zhang Y, et al. Analysis of workflow and time to treatment on thrombectomy outcome in the endovascular treatment for small core and proximal occlusion ischemic stroke (ESCAPE) randomized, controlled trial. Circulation 2016;133: 2279-86 CrossRef Medline

11. Sheth SA, Jahan R, Gralla J, et al. Time to endovascular reperfusion and degree of disability in acute stroke. Ann Neurol 2015;78:584-93 CrossRef Medline

12. Broderick JP, Palesch YY, Demchuk AM, et al. Endovascular therapy after intravenous t-PA versus t-PA alone for stroke. $N$ Engl J Med 2013;368:893-903 CrossRef Medline

13. Ciccone A, Valvassori L, Nichelatti M, et al. Endovascular treatment for acute ischemic stroke. N Engl J Med 2013;368:904-13 CrossRef Medline

14. Kidwell CS, Jahan R, Gornbein J, et al. A trial of imaging selection and endovascular treatment for ischemic stroke. N Engl J Med 2013; 368:914-23 CrossRef Medline

15. Goyal M, Almekhlafi M, Menon B, et al. Challenges of acute endovascular stroke trials. Stroke 2014;45:3116-22 CrossRef Medline

16. Goyal M, Menon BK, Hill MD, et al. Consistently achieving computed tomography to endovascular recanalization $<90$ minutes: solutions and innovations. Stroke 2014;45:e252-256 CrossRef Medline

17. Qureshi AI, Abd-Allah F, Aleu A, et al. Endovascular treatment for acute ischemic stroke patients: implications and interpretation of IMS III, MR RESCUE, and SYNTHESIS EXPANSION trials: a report from the Working Group of International Congress of Interventional Neurology. J Vasc Interv Neurol 2014;7: 56-75 Medline 
18. Aghaebrahim A, Streib C, Rangaraju S, et al. Streamlining door to recanalization processes in endovascular stroke therapy. JNeurointerv Surg 2017;9:340-45 CrossRef Medline

19. Asif KS, Lazzaro MA, Zaidat O. Identifying delays to mechanical thrombectomy for acute stroke: onset to door and door to clot times. J Neurointerv Surg 2014;6:505-10 CrossRef Medline

20. Mehta BP, Leslie-Mazwi TM, Chandra RV, et al. Reducing door-topuncture times for intra-arterial stroke therapy: a pilot quality improvement project. J Am Heart Assoc 2014;3:e000963 CrossRef Medline

21. Eesa M, Menon BK, Hill MD, et al. Achieving faster recanalization times by IA thrombolysis in acute ischemic stroke: where should we direct our efforts? Interv Neuroradiol 2011;17:228-34 CrossRef Medline

22. Menon BK, Almekhlafi MA, Pereira VM, et al. Optimal workflow and process-based performance measures for endovascular therapy in acute ischemic stroke: analysis of the Solitaire FR thrombectomy for acute revascularization study. Stroke 2014;45:2024-29 CrossRef Medline

23. Rai AT, Smith MS, Boo S, et al. The 'pit-crew' model for improving door-to-needle times in endovascular stroke therapy: a
Six-Sigma project. J Neurointerv Surg 2016;8:447-52 CrossRef Medline

24. Zerna C, Assis Z, d'Esterre CD, et al. Imaging, intervention, and workflow in acute ischemic stroke: the Calgary approach. AJNR Am J Neuroradiol 2016;37:978-84 CrossRef Medline

25. van Heerden J, Yan B, Churilov L, et al. Picture-to-puncture time in acute stroke endovascular intervention: are we getting faster? J Neurointerv Surg 2015;7:564-68 CrossRef Medline

26. Brinjikji W, Murad MH, Rabinstein AA, et al. Conscious sedation versus general anesthesia during endovascular acute ischemic stroke treatment: a systematic review and meta-analysis. AJNR Am J Neuroradiol 2015;36:525-29 CrossRef Medline

27. Jumaa MA, Zhang F, Ruiz-Ares G, et al. Comparison of safety and clinical and radiographic outcomes in endovascular acute stroke therapy for proximal middle cerebral artery occlusion with intubation and general anesthesia versus the nonintubated state. Stroke 2010;41:1180-84 CrossRef Medline

28. Takahashi C, Liang CW, Liebeskind DS, et al. To tube or not to tube? The role of intubation during stroke thrombectomy. Front Neurol 2014;5:170 CrossRef Medline 